\title{
Respect and the reality of apparent reasons
}

\author{
Kurt L. Sylvan ${ }^{1}$
}

Accepted: 2 September 2020/Published online: 15 October 2020

(C) The Author(s) 2020

\begin{abstract}
Rationality requires us to respond to apparent normative reasons. Given the independence of appearance and reality, why think that apparent normative reasons necessarily provide real normative reasons? And if they do not, why think that mistakes of rationality are necessarily real mistakes? This paper gives a novel answer to these questions. I argue first that in the moral domain, there are objective duties of respect that we violate whenever we do what appears to violate our firstorder duties. The existence of these duties of respect, I argue, ensures that apparent moral reasons are exceptions to the independence of appearance and reality. I then extend these arguments to the domain of overall reason. Just as there are objective duties of respect for moral reasons that explain moral blameworthiness, so there are objective duties of respect for reasons (period) that explain blameworthiness in the court of overall reason. The existence of these duties ensures that apparent reasons (period) are exceptions to the independence of appearance and reality.
\end{abstract}

Keywords Apparent reasons · Objective reasons · Rationality · Normativity · Respect

Kurt L. Sylvan

k.1.sylvan@soton.ac.uk

1 Philosophy, Avenue Campus, University of Southampton, SO18 1BF Southampton, United Kingdom 


\section{Introduction}

On a familiar view in meta-ethics, rationality requires us to respond to apparent normative reasons, not normative reasons per se. ${ }^{1}$ The popularity of this view owes partly to a view about normative reasons on which they are, in the first instance, facts that count in favor of acts and attitudes. Given this view, it is natural to think that one can fail to be in a position to appreciate all the reasons or the normative relations they bear to one's acts or attitudes while remaining fully rational. If there is any obvious connection between rationality and normative reasons on this sort of view, it is indirect: one is rational only if one responds correctly to the normative reasons that appear to exist from one's perspective.

So understood, rationality has two aspects worth separating. On the one hand, rationality requires us not to ignore our beliefs about what there is reason to do. This dimension of rationality is captured by coherence requirements such as:

Enkrasia:Rationality requires one to $\phi$ if one thinks there is decisive reason to $\phi .^{2}$

While recent literature focuses heavily on such requirements, we can hold that rationality calls for more than coherence even if we agree that it calls for less than correctness. Note that some apparent reasons are generated by appearances of a nondoxastic kind. If it looks like there is a red-hot coil on the stove, there is prima facie rational pressure not to thrust your hand onto it. The pressure is not weaker if the appearance misleads, nor if you lack the explicit belief that there is decisive reason not to burn yourself. ${ }^{3}$

\footnotetext{
1 This view originates in Scanlon (1998). Many others endorse it, including Dancy (2000), Kolodny (2005), Parfit (2001), Raz (2011), and Schroeder (2009).

'Apparent reason' is Parfit's term. I prefer it to 'subjective reason', since I'm not persuaded we should accept a dualism of subjective and objective reasons, with each understood as normative in different ways. But the question on which I focus could be raised in the language of subjective reasons: the question would be whether subjective reasons and obligations have any objective significance, or whether their significance is merely subjective. The only assumptions needed to get the puzzle going are (i) that there is a perspective-independent notion of genuine normativity, and (ii) that it is an open question whether one's perspective necessarily has any perspective-transcendent normative significance. Some might reject these assumptions, but enough philosophers of normativity would grant them that it is worth considering my question.

2 'Enkrasia' is Broome's term. People often discuss this simple version of Enkrasia but recognize that it needs to be reformulated in a more complicated way (see, e.g., Broome (2013)). For these introductory purposes, I bracket the question of how best to formulate the true principle.

There are other norms related to Enkrasia (as stated) that fall within the scope of my discussion. Enkrasia focuses on cases in which one thinks there are decisive reasons to $\phi$. But as Fogal (forthcoming) notes, non-decisive rational pressures could be generated by other normative beliefs. Indeed, any nonenticing reason one seems to have which doesn't seem undercut is an apparent reason one ought rationally to take into account.

${ }^{3}$ I intend the discussion in this paper to be compatible with a range of views about the nature of apparent/subjective reasons; for some options, see Lord (2018), Sylvan (2015), Vogelstein (2012), Whiting (2014), and Wodak (2019). I assume with these theorists that we should reject Parfit (2011)'s simple view that apparent reasons are considerations which would be objective reasons if they were true, and I assume that apparent reasons must be considerations that one is attracted to treat as objective
} 
Extending a familiar idiom, I will call the rational pressures exerted by our de dicto beliefs about reasons structural apparent reasons and the rational pressures exerted by other appearances substantive apparent reasons. While these rational pressures are worth distinguishing, they have something in common: they depend on how things appear to us. Because appearances can deceive, a question arises: do we necessarily gain a real reason to $\phi$ if there is an apparent reason to $\phi$ ?

It is unclear why this would be so. It isn't true in general that apparent Fs are real Fs. So why think apparent reasons necessarily provide real reasons? ${ }^{4}$ Sure, they line up with real reasons in many actual cases. In our world, there is a real reason not to thrust your hand onto what appears to be a red-hot coil: appearances of red-hot coils reliably indicate the presence of red-hot coils. But it is not a necessary truth that perceptual appearances reliably indicate the facts. And so it's unclear why apparent reasons would necessarily provide real reasons.

Failing to see an optimistic answer to our question, many conclude that apparent reasons are no exception to the thought that apparent Fs needn't be real Fs. ${ }^{5}$ On this view, rational pressures do not necessarily provide real reasons. ${ }^{6}$

While this view is tempting, it leaves us with a puzzle. Even from a third-person point of view, it looks like a mistake for someone to $\phi$ when she has decisive apparent reasons not to $\phi$. It is not a merely apparent mistake, one might think. But if apparent reasons are not necessarily real reasons, it would seem not necessarily to be a real mistake. If there was no real case against $\phi$-ing, how could it have been a mistake to $\phi$ ? We can continue to call it a 'mistake of rationality' even if it is not a real mistake, just as we can call a faux pas a 'mistake of etiquette' even knowing that etiquette isn't robustly normative. But that merely gives us another way to describe the puzzle.

The puzzle, then, is simple. If we accept the tempting view that apparent reasons aren't necessarily real, we cannot obviously explain why mistakes of rationality are real mistakes. But if we reject that view, we face an explanatory burden: we must explain what is special about apparent reasons that makes them exceptions to the thought that apparent Fs needn't be real Fs.

Footnote 3 continued

reasons. Only if apparent reasons are understood in that way do they generate pressures of rationality, I argue in Sylvan (2015).

I leave the ontology of apparent reasons open, though I follow many in talking as if apparent reasons are propositions. I will speak of appearances as generating or providing apparent reasons; I leave open whether appearances could $b e$ reasons, but I take 'generate' and 'provide' to suggest distinctness. Finally, I assume it isn't true by definition that appearances cannot sometimes provide objective reasons.

${ }^{4}$ I use 'provide' in deliberately flexible way: I want to allow that one might positively answer my question either by pointing to distinct real reasons which are generated by the apparent reasons, perhaps via a substantive principle linking the two, or by being identical to real reasons. The story I will tell is, I think, best told in the former form. But my view could be developed in either way.

5 See e.g. Scanlon (1998), Kolodny (2005), Raz (2005), Parfit (2011), and Broome (2013).

${ }^{6}$ Following Fogal (forthcoming), I assume there are defeasible pressures of merely structural rationality just as there are such pressures of substantive rationality. But I don't assume, as Fogal believes, that there are no requirements of structural rationality which don't flow from a balance of pressures. Hence I speak about both. 
One might try to sneak between the horns of this dilemma. There is a familiar strategy when it comes to the rational pressure exerted by normative beliefs. ${ }^{7}$ One can understand the requirement to $\phi$ if one believes that there is decisive reason to $\phi$ in a wide-scope way:

Enkrasia-wide: Rationality requires that [if one thinks there is decisive reason to $\phi$, one $\phi s]$.

We can hold that failing to comply with this requirement is a mistake even if the belief is false. For one can comply with this requirement in two ways: by revising the belief or by $\phi$-ing. One might then hope that this proposal will generalize.

Questions remain, however. One central question in the debate about the normativity of rationality is what the reasons for complying with requirements like Enkrasia-Wide would be. The wide-scope approach doesn't answer this question by itself. Indeed, the most prominent wide-scoper confesses that he is unable to find reasons that would explain the force rational requirements appear to have. ${ }^{8}$ There are other reasons to doubt that wide-scoping addresses the fundamental problem. Not all appearances are doxastic. It might appear to one that there is decisive reason to $\phi$ before one has formed the belief that there is decisive reason to $\phi .{ }^{9}$ Such appearances can generate rational pressure: if it non-doxastically appears that there is decisive reason to $\phi$ and it does not appear that there are reasons to mistrust that appearance, then there is rational pressure to $\phi$. But one cannot drop appearances through reasoning in the way that one can drop beliefs through reasoning. If so, this rational pressure will kick in whenever the relevant appearance is present. ${ }^{10}$ Yet there is no less reason to think that non-doxastic appearances can be misleading than to think that beliefs can be false. Perhaps these appearances exert a different kind of rational pressure. But that fact would just show that our puzzle is more general than many assume. I assume, then, that wide-scoping doesn't solve the fundamental puzzle. The core problem isn't just a problem about coherence requirements. It is a broader problem about the normativity of apparent reasons.

How can we solve this puzzle? Many take it for granted that apparent reasons are not necessarily real reasons, though some have recently held that apparent reasons have normative significance by determining what we ought to do in the deliberative sense of 'ought'. ${ }^{11}$ More familiar responses are to (i) tell an error theory, (ii) give an account of the reasons for satisfying wide-scope requirements, or (iii) mimic

\footnotetext{
7 See Broome (1999).

${ }^{8}$ See Broome $(2005,2008,2013)$.

9 See Huemer (2007) and Bengson (2015) for the idea that non-doxastic appearances extend beyond the perceptual case.

${ }^{10}$ Here I rely on a weak version of what Kolodny (2005) calls the 'Reasoning Test'. All my version assumes is that if a rational requirement governing a conflict between states A and B is wide-scope, then one can reason one's way out by dropping A or by dropping B. I don't assume that one must be able to reason from $\mathrm{B}$ to dropping $\mathrm{A}$ and from $\mathrm{A}$ to dropping $\mathrm{B}$.

11 See, e.g., Ross (2012), Kiesewetter (2017), and Lord (2018).
} 
Prichard on the normativity of morality and hold that there are reasons to be rational without giving an explanation that appeals to reasons from another domain. ${ }^{12}$

I am unsatisfied with these proposals. But rather than argue against them, I want to pursue a kind of alternative that has been ignored. This alternative simply maintains that having an apparent reason to $\phi$ does necessarily give one a real reason to $\phi$ and seeks to explain how this is possible.

My account of how this is possible is the Respect-Based Account. ${ }^{13}$ It says that the problem with someone who is irrational is that she violates an objective duty of respect for reasons. To develop this account, I begin in $\$ 2$ with a point that I invoke throughout. Whenever a source of reasons calls for respect, ${ }^{14}$ we find an exception to the idea that having an apparent reason to $\phi$ does not guarantee having a real reason to $\phi$. Specifically, for any source of reasons $X$ that calls for respect, if $\psi$-ing would violate a duty one has to $\mathrm{X}$, then if it appears that by $\phi$-ing one would be $\psi$ ing, one's intentionally $\phi$-ing would violate the duty of respect for $\mathrm{X}$ (other things being equal). ${ }^{15}$ This is because intentionally doing what appears to violate your duties to $\mathrm{X}$ is a way to manifest disrespect for $\mathrm{X}$.

With these ideas in place, I defend a more ambitious claim in $\$ 3$ : whenever one fails to heed apparent reasons, one is violating a duty of respect for reasons. This is because failures to heed apparent reasons will involve doing what, if the appearances were veridical, would amount to failures to respond to the reasons. And such failures preclude full respect for reasons. From this and the preliminary points made in $\S 2$, it will follow that appearances of reasons provide genuine reasons. And these reasons are serious, since they are explained by duties of respect.

One might wonder what this duty of respect for reasons involves and where it comes from. Anticipating these questions, I unpack the notion of respect in $\S 2$ in a way that stymies the worry that it is fetishistic. Following Graham (2014), I suggest that respect for morally relevant factors is a requirement we should already accept to

\footnotetext{
12 Kolodny (2005, 2008a-c) and Raz (2005) pursue option (i). Southwood (2008) and Hussain (MS) prefer option (iii). Many like option (ii), but most give stories for particular coherence requirements rather than giving a general theory for all rational requirements; e.g., Bratman (2009) gives an account of the reason to comply with the wide-scope instrumental principle, while Reisner (2011) gives an account of the reasons to comply with epistemic coherence requirements.

13 This account generalizes a view I've long held in the epistemic case-see Sylvan (2012, 2014, 2018, 2020).

14 'Reason' can refer either to things that stand in reason-relations or to the abstract reasons that they provide. If so, then reasons (in the first sense) can be sources of reasons (in the second sense). Accordingly, I will shift between talking about reasons and sources of reasons, where the latter understood as whatever can give a reason, including people, principles, facts, and so on. I leave open which notion is the key notion, though I suspect that the key notion is the broad source notion. I also think that values understood non-teleologically in the manner of Anderson (1993) and Scanlon (1998: Ch.2) are the relevant sources; hence respect for value is more fundamental, though values are reasons in the source sense.

15 I use this formulation because the point doesn't turn on one's representing $\phi$-ing as duty-violating. 'Other things being equal' covers for whatever other conditions might be necessary for a duty to be relevantly apparent. On sophisticated accounts of apparent reasons like my own in Sylvan (2015), it is not enough for an apparent fact to be an apparent reason to $\phi$ that this fact would, if it obtained, give one a reason to $\phi$.
} 
explain moral blameworthiness. In positing a duty of respect for reasons, I generalize this suggestion to the domain of overall reason: this duty of respect is the duty we violate whenever we are blameworthy in the court of overall reason.

The upshot is that the objective duty of respect explains why there is objective reason to comply with requirements of substantive rationality. I give a similar argument that failing to respond to structural apparent reasons constitutes violation of an objective duty of commitment to reasons-responsiveness, which I formulate to avoid worries about fetishism and rational akrasia. This duty explains the normativity of (enkratic) structural rationality. So two norms explain the normativity of appearance-determined rationality: a norm of respect underpins the normativity of substantive rationality $(\$ 3)$ and a norm of commitment underpins the normativity of structural rationality $(\$ 4)$.

It is compatible with this story that there can be reasons outside a rational agent's ken to which she can fail to conform. But as I explain in $\$ 5$, if this were true, my view wouldn't predict that we face any incredible dilemma. Competing duties can issue from a single locus. Some values are both fittingly respected and promoted, and respect and promotion can conflict. One might wonder, though: if the pressure to conform to all the reasons outweighed the pressure to manifest respect for reasons, would it follow that the requirements of rationality lack stringency? Not, I argue in $\$ 5$, any sort of stringency that anyone should have ever expected of rational requirements. After addressing some other objections, I close by taking stock of the main points and how my account meets the constraints we can reasonably impose on an account of the normativity of rationality.

\section{Respect, obligation, and the appearances}

To warm up to my general account, I will begin by arguing that there is a kind of reason in the moral case for which the following thesis holds:

Weak Transparency-Substantive: Necessarily, if one has a substantive apparent reason of this kind to $\phi$, then one has an objective reason of this kind to $\phi$.

My defense of this thesis turns on a fact about respect. For any $\mathrm{X}$ that calls for respect, if $\psi$-ing would violate a duty one has to $\mathrm{X}$, then if it appears that by $\phi$-ing one would be $\psi$-ing, one's intentionally $\phi$-ing would violate the duty of respect for $\mathrm{X}$. So, if one has that kind of apparent reason not to $\phi$, one has a real reason not to $\phi$. And the reason is serious, since it is explained by a duty of respect.

Notice that I'm not claiming that if it appears to one that some act would violate a duty one has towards $\mathrm{X}$, then intentionally performing that act would violate that very duty. One could call that false claim Strong Transparency. The claim I defend is that there is always a real duty one would violate if one intentionally performed an apparent duty-violating act: viz., a duty of respect.

Using a similar strategy, I will also argue that there is a kind of reason in the moral case for which the following holds: 
Weak Transparency-Structural: Necessarily, if one has a structural apparent reason of this kind to $\phi$, then one has an objective reason of this kind to $\phi$.

This thesis requires separate treatment, since it raises issues that do not arise in the case of Weak Transparency-Substantive.

\subsection{Respect and the appearances}

Let's consider some examples. Relationships demand respect. They demand other things too, which vary depending on the type of relationship. Suppose you and Kris decide to have a monogamous relationship. And suppose that your joint decision makes it the case that you have a duty not to become romantically involved with other people. The crucial thing to notice is that if you intentionally do what appears to violate this duty, you violate a further duty: you fail to manifest the kind of respect for your relationship (and for Kris) that it (and Kris) demand.

To see why this is plausible, consider a case in which it misleadingly appears that you are becoming romantically involved with someone other than Kris:

Disguise: Kris worries that you would cheat if you had the chance. Kris decides to test this hypothesis. With the help of an acting background and some remarkable costuming skills, Kris manages to dress up like a totally different person on whom you would have an instant crush. So disguised, Kris has been showing up at coffee shops around your workplace to flirt with you. You are convinced that you are interacting with someone other than Kris. You now seem to be having a date with this person when Kris allegedly planned to be out of town.

Suppose Kris reveals the truth and claims that you lack respect for your relationship. The following wouldn't be a compelling response: 'Not so: you, after all, are the one on this date with me!'

We would underdescribe this case if we merely say that you did something subjectively wrong. Of course, you did not really violate a duty against cheating on Kris. But you did violate a duty with the same source. Your plans and acts manifested disrespect for your relationship and for Kris. You objectively ought not to manifest such disrespect. The value — the actual value — of your relationship calls for such respect. This case illustrates how the apparent violation of one duty can constitute a real violation of another duty. And so it shows that for one kind of reason, having an apparent reason of that kind ensures having an objective reason of that kind.

While the duty of respect has its source in actual value and is not a merely subjective duty, it imposes a constraint on your subjectivity. You cannot manifest respect for a relationship by intentionally doing what appears to violate the terms of that relationship. Conversely for disrespect: would it cast doubt on your loyalty if you had a date with someone who managed to look and act just like Kris, and whom you took on this basis to be Kris? No. If Kris were unaware that the person with whom you had the date was dressed up this way, Kris could demand an explanation. But you could show there was no failure of respect. 
This observation is not confined to intimate relationships. Other relationshipsthe relationship of promiser to promisee, testifier to recipient, or professional to professional-demand the sort of respect that underpins our observation. Suppose you promised Zane that you will $\phi$ by April. And suppose that it is now January and you misremember: you mistakenly seem to recall promising that you would $\phi$ by February. It turns out that you wrote this mistake into your calendar. If you now make plans to do something incompatible with $\phi$-ing by February and say to yourself, 'Ah, who cares what Zane thinks. I'll do it by April,' you manifest disrespect for Zane and the constraints his promises impose. He could complain if he overheard you, even though your plans would fulfil the promise actually made.

Similar points apply to testimony. Although the recipient of testimony wants truth or knowledge, it doesn't follow that she has nothing to complain about if she receives nothing but truth or knowledge. Even if I realize that a testifier always speaks the truth about some domain, I have something to complain about if the testifier takes himself to be speaking falsely. We care about honesty even if we know we will get the truth anyway. Why? Because, again, a norm of respect is in play.

The observation isn't confined to relationships. Legitimate rules call not only for conformity but for respect. A person might conform to a rule but do so despite being reckless or negligent with respect to it. When we fault this person, what we are faulting them for is for manifesting insufficient respect for the rule. That is a real mistake. These observations suggest that when a person has apparent reason relative to some rule to intend to $\phi$, then insofar as that rule is normative, she has real reason to intend to $\phi$ : failure to intend to $\phi$ would manifest disrespect for the rule.

So there is a kind of objective reason one cannot appear to have without having a reason of that kind. Of course, there is room for a more specific kind of fallibility. It is false that if it appears to us that we are cheating on our partners, breaking our promises, speaking falsely, or violating some principles, we are thereby making these mistakes. But it doesn't follow that we aren't thereby violating other objective duties.

This point is often overlooked in discussions of the relationship between blameworthiness and wrongness, with the exception of Graham (2014). Excusable wrongdoing is possible, and it is true that one can be blameworthy in doing something permissible. ${ }^{16}$ But it doesn't follow that all norms can be blamelessly violated or that there is no norm one violates when one is blameworthy in performing a permissible act. The norm one violates is a norm of respect. And norms of respect cannot be blamelessly violated.

\subsection{The nature and objects of respect}

What is the relevant sort of respect? It needn't be second-personal: it is something that one can have with respect to a legitimate rule. It is closer to the broader sort of

\footnotetext{
16 The latter is more controversial than the former. For a defense of the idea that one can be blameworthy in doing something permissible, see Zimmerman (1997).
} 
recognition respect Darwall (1977) had in mind, though I hesitate to use the term because he uses it second-personally in his more recent work. ${ }^{17} \mathrm{He}$ originally described recognition respect for $\mathrm{X}$ as 'a disposition to weigh appropriately in one's deliberations some feature of $[\mathrm{X}]$ and to act accordingly. ${ }^{18}$ Weighing the feature appropriately, as our examples suggest, means weighing it in the way that the appearances suggest ( $d e$ re) to be the right way. More precisely, I suggest the following specification of the conditions under which one manifests respect for a source of reasons:

Manifesting Respect: $S$ manifests respect for a source of reasons $R$ iff $S$ complies with the substantive apparent reasons apparently given by $\mathrm{R}$.

This isn't intended to be an analysis but rather a specification of the conditions under which one manifests respect. To have respect for a source of reasons might then be regarded as having the disposition to manifest respect for that source of reasons.

We have seen that this sort of respect can take partners, promisees and interlocutors as objects. These objects of respect are denizens of concrete reality. Still, not every claim of the form 'S manifests respect for X-es' entails a claim of the form 'There exist some X-es for which $\mathrm{S}$ manifests respect'. Even if all (nonhuman) animals vanished, one person might manifest a disrespect for animals that the other doesn't. Suppose Audrey and Blanche are unaware that all animals have vanished, and that there are holograms of cats designed to trick them into thinking that some animals remain. Imagine now that Audrey sees a hologram of a cat being bashed and thinks a real cat is being bashed. If Audrey rejoices, we should resent her. What for? Plausibly, for her disrespect. If, by contrast, Blanche seemed to see that she could prevent a cat from being bashed and aimed to do so, she would manifest respect. It is hard to see why Audrey should be less blameworthy for her response or Blanche less praiseworthy for her response than if real cats were involved.

Does it follow that the requirements of respect that fundamentally underpin blameworthiness are more abstract than the surface attributions suggest even when relevant concreta exist? It is tempting to say 'yes', though one might question the general principle behind this temptation, as disjunctivists do. More cautiously, we can say that even if we are required to respect the relevant concreta when they exist, it doesn't follow that we lack an equally strong duty of respect when these concreta are missing. We have such duties, and this fact explains why Audrey is blameworthy and Blanche isn't. Is it fetishistic to believe in this duty of respect? No. It must be in place to explain the full range of blameworthiness/praiseworthiness facts. If avoiding such disrespect were no duty, it is unclear why Audrey would be blameworthy.

Such a norm would be fetishistic only if it interfered with our caring about concreta. But we aren't forced to think it does. By analogy, we aren't forced to think

\footnotetext{
17 Esp. Darwall (2006).

18 Darwall (1977: 38).
} 
that experience gets in the way of our seeing things if we grant that we would have the same experience when hallucinating. Disjunctivists may disagree, but they aren't obviously right. Just as we see things in normal cases partly by occupying a state we could occupy even when hallucinating on non-disjunctive views, so we manifest respect for concreta in normal cases partly by occupying a state that we could occupy even when hallucinating these concreta. Respect for animals doesn't get in the way of caring about particular animals even if it supervenes on the internal, just as experience doesn't get in the way of seeing particular animals even if it supervenes on the internal.

\subsection{Commitment and normative appearances}

So far we've been discussing a kind of respect that one can seemingly manifest even in the absence of any relevant normative beliefs. Audrey manifests disrespect for non-human animals even if she lacks the belief that her reaction is wrong, and Blanche manifests respect even if she lacks the belief that her response is right. Our picture of respect respects this fact: substantive apparent reasons aren't de dicto appearances of reasons. Still, one might think that there is something bad about believing that one has a duty to $\phi$ and failing to $\phi$. What could explain that? Is there another norm that enjoins de dicto care?

\subsubsection{Praiseworthy akrasia?}

Let's back up. Answering these questions requires care because some hold that one's responsiveness to normative beliefs in $\phi$-ing has little or no impact on one's praiseworthiness or blameworthiness in $\phi$-ing. Arpaly (2003) defended such a view. There are also well-known claims to the effect that de dicto concern for rightness is fetishistic (Smith (1994)). I agree with existing responses to Arpaly and Smith. I'll briefly discuss some to bring into focus the norm that answers our questions. ${ }^{19}$

Recall one of Arpaly's arguments that acting against one's normative beliefs isn't necessarily blameworthy. Huck thinks turning Jim in is the right thing and feels pangs of conscience when he is loyal to Jim. His decision not to turn Jim in seems praiseworthy when understood as a manifestation of genuine sympathy. Yet Huck acts against his belief that it is wrong to do so, and so allegedly acts akratically. Notably, Arpaly describes Huck as undergoing a 'perceptual shift' in the time he spends with Jim, and as manifesting a 'visceral egalitarianism'.

This case may recommend the conclusion that it is possible to judge that $\phi$-ing is wrong while nonetheless being praiseworthy in $\phi$-ing. But it is important to noteand here I follow Smith (2004) - that this praiseworthiness is best viewed as a global or overall kind of praiseworthiness. That Huck is praiseworthy in this sense is compatible with the thought that Huck is failing to comply with a local duty of respect. For one can take overall praise and blame to reflect one's compliance or

${ }_{19}$ Below I discuss some old responses; for an outstanding new response, see Johnson King (2020a, b). 
lack of compliance with a whole range of local duties of respect. And there are numerous such duties with which Huck is complying.

There are other reasons to doubt that this case shows that there is no duty of responsiveness to de dicto normative appearances. Firstly, as Kriegel (2012) observes, it is natural to regard Huck as having the implicit attitude that turning Jim in is wrong. The earmarks of such attitudes will be present if we understand the case as Arpaly does (perceptual shift and all). ${ }^{20}$ Absent the case for attributing the implicit attitude, Huck might not be praiseworthy. But then the case would suggest that responsiveness to de dicto normative implicit attitudes is necessary for praiseworthiness. Secondly, as Holton (MS) observes, it is unclear that Huck has any stable relevant normative beliefs at the time of action. If not, the case is no counterexample to the thought that acting against the de dicto normative appearances renders one blameworthy. Finally, as Arpaly agrees, Huck would be more praiseworthy if he had the knowledge that it is right to help Jim and acted from it: she just denies that this is necessary for him to be praiseworthy.

For all we have seen, then, it would be reasonable to maintain that there is a local duty with which Huck fails to comply, where that fact renders him open to local criticism even if his choice is praiseworthy in a global sense.

\subsubsection{Fetishism?}

What is this duty? In answering this question, we must avoid a different worry about celebrating responsiveness to normative beliefs. Respect is a form of de re concern, and involves responding to non-normative appearances. De dicto normative appearances are another matter. If responding to them grounds a form of concern, one might worry that it is a fetishistic concern for rightness as such.

I believe this worry was compellingly answered long ago. It isn't clear that the only alternative to de re concern is a first-order concern for acting rightly as such. Dreier (2000) pointed to a further alternative. ${ }^{21}$ Rather than requiring the first-order desire to perform right actions for the sake of performing right actions as such, one could require a second-order desire with the following form:

(*) One desires that [if $\phi$-ing is morally right, one desires that [one $\phi$ for its own sake]].

Being guided by $(*)$ is compatible with acquiring de re desires to perform particular right actions for their own sake. Yet one side of the fetishism worry is that having the de dicto desire will preclude de re caring about right-making features for their own sake. If we enshrine the relevant form of concern in a second-order desire like (*), this worry evaporates. The proponent of the fetishism charge might complain

\footnotetext{
${ }^{20}$ Some theories of apparent reasons require one to have what is naturally understood as the implicit attitude that there is sufficient objective reason to $\phi$ if one is to have sufficient apparent reason to $\phi-i$.e., that one treats one's situation as one in which there is sufficient objective reason to $\phi$. See e.g. Lord (2018).

21 Dreier discusses two alternatives. I mention the second; see Dreier (2000: 635-38).
} 
that we have merely moved the lump under the rug. But as Dreier observed, this complaint is unjustified. The second-order desire is hardly objectionable:

If [someone] were told that some day in the future she will see clearly what features of actions are the right-making ones, and asked whether she hopes that she will be moved by these features, she surely must say that she does hope so. Otherwise she could hardly be called a good moral agent. So it is not $[(*)]$ itself that provides any ground for complaint. ${ }^{22}$

What might be objectionable is if the first-order desires had to be sustained by the second-order desire. But we aren't committed to recommending that dependence. While the original cause of the first-order desires will be the second-order desire, they can be sustained just by de re awareness of the right-making features. So, there is a non-fetishistic alternative to first-order de dicto concern for rightness.

The fetishism objection to first-order de dicto concern doesn't withstand scrutiny anyway. ${ }^{23}$ This concern would be fetishistic if it were one's sole non-instrumental concern, so that one's de re concerns were merely instrumental. But the relation between the de dicto and de re concerns need not be instrumental. If the relation isn't instrumental, the appearance of fetishism disappears. De dicto concern isn't fetishistic as such. It is only fetishistic when it plays a certain role-when it interferes with non-instrumental caring about particular right actions or valuable things.

\subsubsection{Commitment}

While the fetishism objection to first-order de dicto concern fails, I prefer a version of Dreier's approach. I want the relevant concern to be a concern one fails to manifest when akratic. I'm unsure that $(*)$ is a desire that one cannot manifest when akratic. Mightn't an akratic agent desire that they not be akratic and manifest this desire by bemoaning their akrasia? If so, then if there is something objectionable about akrasia, it isn't that this desire is missing or not manifest. It is better, I think, to claim that what is missing is the manifestation of a second-order commitment to intending to perform right actions for their own sake. ${ }^{24}$ We can replace $(*)$ with:

$(* *)$ One has the commitment that [if $\phi$-ing is morally right, one intends to $[\phi$ for its own sake]].

One could have this commitment while being occasionally akratic at the first order. But one could not manifest it in being akratic. One doesn't manifest commitment to intending to $\phi$ if $\phi$-ing is right by bemoaning one's akrasia. What one bemoans is that one isn't manifesting that commitment!

\footnotetext{
22 Dreier (2000: 636).

23 Others have made the point to follow; cf. Brink (1997) and Dreier (2000). See Johnson King (2020b) for a further defense of de dicto concern.

24 This is psychological commitment, not the normative commitment Shpall (2014) discusses.
} 
It is plausible that the commitment one finds lacking in those who are insensitive to apparent rightness is the commitment picked out in (**). This commitment isn't fetishistic. If we think people are open to local blame for acting against their beliefs about rightness, we are committed to thinking that rightness calls for such commitment. While there are doubters, their doubts are unfounded, at least if understood as doubts about the modest thought that one is open to local blame when akratic.

I suspect that what is happening in apparent cases of rational akrasia is that one isn't fully responsive to the substantive apparent reasons: if one were, one wouldn't have the false normative belief. The apparent reasons Huck has against turning in Jim are apparent evidence against his false belief. So it is hard to see how Huck could have sufficient apparent reason to think that he should turn in Jim in the relevant case.

\subsection{Assessing weak transparency-structural}

I've addressed what I take to be the main reasons for rejecting a local norm of $d e$ dicto commitment to reasons-responsiveness. Granting that there is such a norm, how does it bear on whether structural apparent reasons are real reasons?

So far I've been primarily interested in showing that (i) one can be locally blameworthy for akrasia and that (ii) the norm one violates here is a local norm of commitment to reasons-responsiveness. If (i) and (ii) are true, we still strictly speaking only get a reason not to be akratic. That alone, one might think, doesn't get us the detached reason to act.

To get the detached reason, we can attend to two further points. Firstly, when the appearance is non-doxastic, there will be only one way to avoid conflict through reasoning. So the pressure will be detachable. Secondly, when the appearance is doxastic, we still get a serious reason to adopt the attitude given the belief: we just also get an equally serious reason to drop the belief. ${ }^{25}$ By the lights of the norm of commitment, there is no stronger reason for either option. That isn't to say that there is no serious reason to $\phi$ (given the belief). ${ }^{26}$ This is a surprising claim in itself. Some think it alone yields unacceptable bootstrapping. ${ }^{27}$ But we should accept it with some qualifications to be discussed in $§ 4$. Carefully understood, it doesn't yield an unacceptable kind of bootstrapping. Indeed, it is plausible that if one's normative belief is false, one will have sufficient apparent reason to drop that belief and the norm of respect will push one in that direction.

\footnotetext{
25 Notice that I'm not claiming that one gets a reason to adopt the attitude when the doxastic appearance is not in place. I'm not relying on the principle that if one has reason to make it true that $[p$ or $q$ ], one has a reason to make it true that $p$ and a reason to make it true that $q$, which Rippon (2011) undermined.

${ }^{26}$ Cf. Schroeder (2005) on Raz (2005).

27 Cf. Raz (2005).
} 


\section{Generalizing, part I: respect and substantive rationality}

\subsection{The thesis}

The claims defended in the previous section were restricted in certain ways. I turn now to generalize, beginning with a defense of the following broader relative of the last section's first core thesis:

Weak Transparency-Substantive +: Necessarily, if one has an undefeated serious substantive apparent reason to $\phi$, one has a serious objective reason to $\phi$.

Two remarks about the scope of this thesis are in order. The first is about why 'undefeated' is in the antecedent and not the consequent. It is in the antecedent because the thesis would be indefensible without it there. I want to explain why apparent reasons matter by appealing to an ideal of respect for objective reasons. Acting against undefeated serious apparent reasons manifests disrespect for objective reasons. Not so for defeated apparent reasons: acting for them manifests disrespect for objective reasons and ignoring them manifests no obvious disrespect. So I reject the principle that drops 'undefeated' from the antecedent.

If 'undefeated' is in the antecedent, why isn't it in the consequent? Because there can be rebutting defeaters beyond one's ken that outweigh the reasons one gets from the norm of respect. ${ }^{28}$ This fact does raise questions about how to understand the stringency of substantive rationality, which I address in $\$ 5$.

The second remark to make is about what 'serious' means. I've been using 'serious' as if it were synonymous with 'weighty'. The reason why 'seriousness' so understood has played a role is that I don't want to defend the uninteresting claim that there is some trivial objective reason to heed apparent reasons: the claim is rather that if there is a serious apparent reason to $\phi$, there is a similarly serious objective reason to $\phi$.

There is something else that 'serious' could indicate. One might think that it isn't at all irrational to ignore apparent undefeated enticing reasons. ${ }^{29}$ So, if one wants to explain why apparent reasons are real reasons by appeal to some ideal of respect for reasons, one might wonder how the story goes for enticing reasons. Frankly, though, I'm skeptical that apparent enticing reasons to $\phi d o$ necessarily yield objective reasons to $\phi$. The project of explaining their normativity strikes me as less pressing than the project of explaining the normativity of apparent peremptory reasons. Indeed, the former project is obviously not part of the standard project of vindicating the normativity of rationality. So by 'serious', I'll mean not merely enticing. (Note that peremptory reasons are still defeasible.)

\footnotetext{
${ }^{28}$ I don't think there can be objective undercutting defeaters in the relevant cases: respect-based objective reasons give one a safeguard against them. A totally objectively undercut reason is not really an objective reason. But the norm of respect will convert an undefeated apparent reason into an objective reason.

29 On enticing reasons, see Dancy (2004).
} 


\subsection{The argument in outline}

With these clarifications in mind, let's consider the argument that I will use to defend Weak Transparency-Substantive + .

The respect argument

1. There is an objective duty to manifest respect for objective reasons.

2. One manifests respect for objective reasons iff one heeds undefeated serious apparent reasons.

3. So, there is a derived objective duty to heed undefeated serious apparent reasons.

4. If (3), then if one has an undefeated serious apparent reason to $\phi$, one has a serious objective reason to $\phi$.

5. So, if one has an undefeated serious apparent reason to $\phi$, one has a serious objective reason to $\phi$.

I'll devote $\$ 3.3$ and $\S 3.4$ to defending (1) and (2). Since (3) follows from (1) and (2), (4) is obvious, and (5) follows from (3) and (4), that defense will secure the argument.

\subsection{Defending (1): domain-relative blameworthiness, overall blameworthiness, and respect}

What is the duty of respect for objective reasons? Why think we have this duty?

Let's back up. It is plausible that for every domain (e.g., morality, prudence, epistemology...), there is a norm of respect for the reasons in the domain, where these reasons are the things that bear the domain-relative reason-for relation to acts and attitudes. What makes these various norms of respect belong to a unified class is their role. The norm of respect for moral reasons explains the force of assessments of moral blameworthiness and praiseworthiness. The norm of respect for prudential reasons explains the force of assessments of prudential blameworthiness and praiseworthiness. The norm of respect for epistemic reasons explains the force of assessments of epistemic blameworthiness and praiseworthiness. Etc.

One might doubt that there is such a thing as non-moral blameworthiness. But this doubt is only terminologically justified. Perhaps 'blame' is the wrong word because it has a special tie to reactive attitudes like resentment and indignation. But it doesn't follow that in other domains, there is no functional analogue of blame. In every domain, there is a distinction between inexcusable and excusable first-order norm violation. If there is no apparent reason to think that by $\phi$-ing you would be $\psi$ ing, where $\psi$-ing would violate some norm, you are ceteris paribus excusable for $\phi$ ing if $\phi$-ing in fact violates this duty. If there is sufficient apparent reason to think that by $\phi$-ing you would be $\psi$-ing, where $\psi$-ing violates some norm, your $\phi$-ing is ceteris paribus inexcusable.

One is excusable in the domain in the same conditions in which one avoids violating the relevant norms of respect in the domain. One is inexcusable in the 
domain in the same conditions in which one violates such a norm. The reason why the analogues of blame have force is that they amount to pointing to the fact that one has violated a norm of respect in the domain. Of course, it is possible to do something blameworthy while doing (accidentally) what the first-order reasons in the domain favor. But it doesn't follow that there isn't any objective norm one violates when one is blameworthy.

Whether one wants to mark the more general contrast between inexcusable and excusable first-order norm violation using 'blame' talk is a terminological matter. There are analogues of blame-things that play a similar role-in other domains. To say that these things play a similar role to blame isn't to say that all the roles of blame are paralleled: they just parallel each other in carving out the inexcusable/ excusable violation distinction. So, I think we have as much reason to think that there are norms of respect for objective reasons in non-moral domains as there is to think that there is a norm of respect for objective reasons in the moral domain.

Now, I've talked as if there is some overarching norm beyond particular norms of respect in particular domains. On an opposing view, there is just a collection of norms of respect in various domains. This view is simpler. Is that reason to withhold belief in my view?

Only if there are no appraisals to explain that cannot be explained by particular norms of respect in particular domains. But there must be such a thing as blameworthiness and praiseworthiness in the court of overall reason. Reasons of morality and reasons of prudence, apparent or otherwise, can be balanced to yield an overall fact about what one has most reason to do. We should expect there to be a distinctive appraisal we can make of someone who fails to heed the balance of apparent reasons (all domains considered), and someone who heeds the balance of apparent reasons (all domains considered).

One way to describe these appraisals is with the phrases 'blameworthiness in the court of overall reason' and 'praiseworthiness in the court of overall reason'. This yields a nice symmetry. But there are ordinary words that do the job: namely, 'irrationality' and 'rationality'. We need a norm of respect to explain the force of these appraisals. The norm is the norm of respect for objective reasons (period).

So, we have good reason to accept premise (1) in the Respect Argument. We are already committed to norms of respect for the reasons of particular domains by our practice of agent-directed criticism and praise for each domain. But we have a need for assessments that reflect the balance of these norms of respect-a need for praise and blame in the court of overall reason. Those assessments just are assessments of substantive rationality. The duty of respect for objective reasons is what backs those assessments.

\subsection{Why heeding apparent reasons fulfils this duty}

How can the duty of respect for objective reasons back assessments of substantive rationality? How — as premise (2) says — can heeding apparent reasons be a way to manifest respect for objective reasons?

Remember that one can manifest disrespect for animals even if there are no particular animals that one is disrespecting. Hence, if it supports resenting Audrey, 
the requirement to not manifest disrespect for animals must not presuppose that there are any animals toward which Audrey manifests disrespect. Perhaps Audrey would be more blameworthy if a real cat were being run over. But she is still blameworthy for her reaction. So there is a duty of respect that she violates.

We can generalize this observation: similar points can be made about other examples in the moral case and about examples in non-moral cases. For every kind of blameworthiness we can imagine, there will be a corresponding norm of respect, where the sort of respect that figures in that norm can be manifest toward Fs even if there are no actual Fs. It will be a requirement of respect for moral reasons that one can violate even if one isn't disrespecting any standard concrete providers of moral reasons. Now, suppose that charges of substantive irrationality simply amount to charges of blameworthiness in the court of overall reason. And suppose that the fundamental requirement in the court of overall reason is the requirement to correctly respond to the overall balance of objective reasons. Then it will be plausible that what underpins charges of substantive irrationality is the requirement of respect for objective reasons (period). One can violate this requirement even if one isn't disrespecting any concrete providers of objective reasons (period).

Just as one can manifest disrespect for objective moral reasons by failing to heed the apparent moral reasons, so one can manifest disrespect for objective reasons (period) by failing to heed the apparent reasons (period). So, while premise (2) in the Respect Argument can sound incredible on first blush, it is perfectly sensible on second blush. Once we note that respecting Fs doesn't require there being any particular Fs that one respects, we find that there is a clear case for (2).

\section{Generalizing, part II: commitment and structural rationality}

\subsection{The thesis and the argument in outline}

The point of this section will resemble that of the last. The point will be to defend the following generalization of the second core thesis from $\S 2$ :

Weak Transparency-Structural+: Necessarily, if one has an undefeated serious structural apparent reason to $\phi$, one has a serious objective reason to $\phi$.

The argument for this thesis parallels the Respect Argument:

\section{The commitment argument}

1. There is an objective duty to manifest commitment to objective reasonsresponsiveness.

2. One fulfils this duty iff one heeds one's de dicto beliefs about the presence of undefeated serious objective reasons.

3. So, there is a derived duty to heed one's de dicto beliefs about the presence of undefeated serious objective reasons.

4. If (3), then if one has an undefeated serious structural apparent reason to $\phi$, one has a serious objective reason to $\phi$. 
5. So, if one has an undefeated serious structural apparent reason to $\phi$, one has a serious objective reason to $\phi$.

My defense of this argument will sound familiar. I will devote $\$ 4.3$ and $\$ 4.4$ to defending premises (1) and (2). I'll also address some worries about (4) in \$4.4. Since (3) follows from (1) and (2), and (5) follows from (3) and (4), this will suffice to defend the argument.

\subsection{Commitment to objective reasons-responsiveness}

What is the duty of commitment? Why think that we have this duty?

Let's back up again. It is plausible that for every domain (morality, prudence, epistemology, etc.), there is a second-order duty that one manifest commitment to heeding first-order reasons in the domain. What makes these various duties of commitment belong to a unified class is their role. The duty of commitment to moral reasons-responsiveness explains the force of ascriptions of recklessness and conscientiousness in the moral domain. The duty of commitment to prudential reasons-responsiveness explains the force of ascriptions of recklessness and conscientiousness in the prudential domain. The duty of commitment to epistemic reasons-responsiveness explains the force of ascriptions of recklessness and conscientiousness in the epistemic domain. Etc.

As I granted in $\$ 2$, recklessness is at best one local dimension of blameworthiness and conscientiousness is at best one local dimension of praiseworthiness. It is compatible with violating a duty of commitment that one is praiseworthy in a global sense. It is also compatible with complying with a duty of commitment that one is blameworthy in a global sense. But none of this shows that there is no duty of commitment. It only shows that duties of commitment aren't the only duties to consider when determining whether someone is blameworthy or praiseworthy. Duties of respect also play a role.

To determine how much weight considerations of commitment have in global assessments of praiseworthiness and blameworthiness, we need to know more about what the norms of commitment require and which kinds of recklessness are incompatible with these norms. I've already suggested that in the moral case, the norm calls for manifesting the following second-order commitment:

(**) One has the commitment that [if $\phi$-ing is morally right, one intends to $[\phi$ for its own sake]].

Hence, the norm of commitment in the moral case is the following:

(MC) One ought morally to have and manifest one's commitment that [if $\phi$ ing is morally right, one intends to [ $\phi$ for its own sake]].

In $\S 2$, I suggested that it is impossible to manifest this commitment through recklessness. As I noted in discussing Arpaly's argument, it isn't obvious what level of acceptance matters for determining whether someone is reckless. Is it reckless to act against one's explicit judgment that $\phi$-ing is morally right if one has a powerful competing implicit attitude or felt attraction toward the proposition that $\phi$-ing isn't 
morally right? Maybe. But perhaps it is more blameworthy if one acts against normative implicit attitudes or felt attractions to assent to propositions. I'll not try to settle which level of acceptance matters most for determining whether someone has violated the norms of commitment. I point to the variety of levels only to stress that the norm of commitment may be more obviously relevant to overall praiseworthiness and blameworthiness if we take other levels than the explicit into account.

What matters more for now is that within each domain, there is a norm of secondorder commitment to first-order reasons-responsiveness that grounds assessments of recklessness and conscientiousness. Given this point, it is easy to defend (1) in the Commitment Argument in the same way that we defended (1) in the Respect Argument.

Again, it would be simpler to claim that there is no norm of commitment to objective reasons-responsiveness beyond particular norms of commitment in particular domains. But parsimony only yields a reason to reject such a norm if there are no appraisals whose force we need such a norm to explain. There is such a thing as recklessness from the point of view of overall reason. To determine whether someone is reckless from the point of view of overall reason, we need to attend to this person's views about what she has overall reason to do. What is 'recklessness from the point of view of overall reason'? It's just another name for the canonical form of structural irrationality: akrasia.

Conversely for conscientiousness. If one thinks at every level that commonsense morality isn't normative, it would hardly manifest conscientiousness if one did what one believed commonsense morality required anyway because one thought commonsense morality required it. To determine whether one is conscientious full-stop, we need to attend to one's views about what one has overall reason to do and how these views affect one's decisions or thoughts. What is 'conscientiousness full-stop'? It's just another name for the canonical example of structural rationality: namely, enkrasia.

We could have arrived at our conclusion on other grounds. We will fail to fully describe normative reality if we only describe what the various normative domains require. Perhaps the most important normative facts are facts about how the reasons from various domains weigh up to yield facts about what there is overall most reason to do. We should expect there to be corresponding appraisals that turn on what there is overall most structural apparent reason for a particular agent to do and how well the agent is responding to these structural apparent reasons. These appraisals need to be backed by a norm of commitment just as much as appraisals of conscientiousness, hypocrisy, and recklessness within particular domains need to be backed by domain-relative norms of commitment.

\subsection{Being enkratic and meeting the duty of commitment}

So much for a defense of premise (1). Premise (2) in the Commitment Argument is more straightforward than premise (2) in the Respect Argument. It is clear that one can manifest one's commitment to norm-responsiveness without conforming to the norm to which one is manifesting commitment, so long as that non-conformity was unexpected. I can manifest my commitment to driving legally by always driving in 
the ways that I believe to be legally permitted. But sometimes I might be mistaken about what is legally permitted. The speed limit might change without my receiving any notice. So manifesting my commitment may not guarantee that I drive legally.

If conformity isn't required for one to manifest commitment to a norm, what is required? The obvious answer is that what is required is that (i) one be so disposed that if there are decisive structural apparent reasons relative to the norm to $\phi$, one $\phi$ $\mathrm{s}$, and (ii) one manifest this disposition. But one has to be enkratic with respect to the norm to meet these conditions. The norm to which one is manifesting commitment when one satisfies enkratic requirements is the norm of objective reasons-responsiveness. Hence, satisfying enkratic requirements is the way to fulfil the duty of commitment.

\subsection{Some worries about (4) addressed}

I turn to address some worries about (4). One worry stems from the thought that it is usually possible to remove the pressure of a structural apparent reason by dropping the belief that generates it. If so, how can an apparent reason to $\phi$ together with the duty of commitment ever provide one with an objective reason to $\phi$ ?

The question rests on a confusion. If there is a duty to $\phi$ when one $\psi s$, then if one is $\psi$-ing, there will be a reason to $\phi$. The fact that the existence of this reason is conditional on one's $\psi$-ing doesn't show that it isn't a reason. There is some reason to speak French when in France. If one is in France, one could leave and thereby escape the pressure to speak French. But one does have a reason to speak French as long as one remains in France. That this reason would cease to exist when one leaves France doesn't mean that it isn't there when one is in France. Since we are granting that there is a duty to manifest commitment to reasons-responsiveness, we have an answer to the worry.

But what if the best way of understanding structural apparent reasons is the widescope way? Aren't we then committing the fallacy of detachment? While there is a fallacy of detachment in the case of wide-scope all-things-considered oughts, there is no obvious fallacy of detachment for wide-scope reasons. Yes, it doesn't follow from the claim that one all-things-considered ought to $[\phi$ if one $\psi$ s] and the claim that one is $\psi$-ing that one all-things-considered ought to $\phi$. Perhaps one should not be $\psi$-ing. But even if one should not be $\psi$-ing, it could be true that there is a serious reason to $\phi$.

Plausibly, a reason remains: one would be meeting the duty of commitment by $\phi$ ing. It would be better if one dropped the belief and avoided meeting the duty of commitment in this way. But the fact that one would be meeting the duty of commitment by $\phi$-ing is a serious reason anyway, even if it is outweighed by whatever overwhelming reason there might be not to $\phi$. This is not to say that the duty of commitment is less stringent than whatever overwhelming reason outweighs the detached reason. That detached reason will not have the deontic force of the duty of commitment that generates it because heeding one's belief here isn't necessary for meeting the duty, but just sufficient.

What if the belief is unalterable? Here it is false that heeding the belief will necessarily facilitate manifesting commitment. Suppose you have a compulsive 
belief that you must shower 10 times after eating tomatoes. You know it is a compulsive belief, but you cannot get yourself to drop it. I cannot see how heeding this belief could manifest commitment to objective reasons-responsiveness. This fact suggests that the norm of commitment doesn't vindicate an unrestricted version of Enkrasia on which you are rationally required to heed your belief that you ought to $\phi$ by $\phi$-ing even when that belief is itself structurally irrational. But we should reject that version.

What if the belief is unalterable but not structurally irrational? ${ }^{30}$ I find it hard to see how a belief could be unalterable but structurally rational ex post. For if this belief is unalterable, it wouldn't be revisable in response to shifts in the balance of structural apparent reasons to the contrary. Even if it isn't structurally irrational, this belief is not structurally rational ex post: unalterability undermines rational control, which is plausibly a precondition for ex post assessment. ${ }^{31}$ But we shouldn't accept an unrestricted form of Enrkasia on which we ought rationally to heed beliefs that are not structurally rational.

\section{Objections answered (and desiderata clarified)}

Having sketched and positively defended my view, I turn to answer some objections. In doing so, I will clarify some familiar but unclear desiderata on accounts of the normativity of rationality, and show that my account satisfies them.

\subsection{What about stringency?}

It is often said that a satisfactory account of the normativity of rationality must explain its apparent stringency: the genuinely normative requirements that it provides must be strict. One might think my view does not satisfy this desideratum. It was supposed to explain the objective normativity of substantive apparent reasons. But, of course, substantive apparent reasons might rationally require one to refuse to do something there is overwhelming objective reason to do. For example, the appearances might suggest that the glass is filled with poison when it is in fact filled with an elixir that will cure all my ills. Here it would be irrational for me to drink from the glass even though there is overwhelming objective reason for me to drink from the glass. If so, how can I claim that we have anything more than a trivial objective reason to drink from the glass?

Reply. The apparent force of this objection rests on assumptions about stringency that everyone should reject. The objection also gets the dialectic wrong. Everyone should think (i) that there are some detachable rational pressures (viz., substantive apparent reasons), (ii) that the puzzle about the normativity of rationality extends to these pressures, and (iii) that these pressures can be outweighed by unapparent

\footnotetext{
30 Setiya (2007) and Schroeder (2009) draw attention to these cases.

31 Since I assume that assessability for ex ante (ir)rationality requires assessability for ex post (ir)rationality, I think we can drop the 'ex post' qualifier; for some views that vindicate this assumption, see Sylvan (2015) and Sylvan and Sosa (2018).
} 
objective reasons. So, everyone must agree that there can be a stronger objective reason to do what substantive rationality requires us not to do. If so, stringency cannot be understood as the objection assumes. More specifically, the following cannot be the way to understand objective stringency:

Conclusive Objective: If a norm has objective stringency, then there are conclusive objective reasons to comply with this norm.

What could stringency involve, if not backing by conclusive objective reasons?

My answer relies on three suggestions: (1) there are independent illustrations of stringent objective norms that can be objectively outweighed, (2) we have good reason to treat the norms of respect that give force to charges of blameworthiness in particular domains as further illustrations, and (3) all the crucial points about these norms extend to the norms of respect that give force to charges of irrationality. The norms of respect that underpin blameworthiness show that the puzzle about stringency is more general than is often supposed. But the puzzle is solvable once we see that there is a familiar category of the strict-but-outweighable of which norms of respect are an illustration. ${ }^{32}$

The duty to keep one's promises provides support for (1). Consider an example from Shpall (2014: 159). Imagine that President X promises to repeal a law but fails to even try to keep this promise. Even if there were stronger objective reasons to keep the law in place, $\mathrm{X}$ gives us sufficient grounds for a complaint. It cannot be grounded merely in some slack, trivial reason. After all, there is slack, trivial reason for him to give everyone candy. But if $\mathrm{X}$ ignores this reason, no one can lodge a similar complaint. The natural conclusion is that there is such a thing as the strict but outweighable. The slack/stringent distinction isn't the same as the outweighable/conclusive distinction. Dancy's enticing/peremptory distinction provides one way to understand this. An older way is to think that it is possible to have a duty to $\phi$ even if there are stronger objective reason not to $\phi$.

We already have the key to understanding what this distinction is tracking. It is present in the description of the case: it is proper to fault $\mathrm{X}$ for failing to try to fulfil his promise even if there are sufficient reasons not to fulfil it, but improper to fault $X$ for not even trying to give everyone candy. More generally:

Faultworthy: If a norm $\mathrm{N}$ has objective stringency, then if it appears that one can only heed $\mathrm{N}$ by $\phi$-ing and one doesn't $\phi$, it is proper to fault one for not $\phi$ ing.

This constraint on stringency poses no problem for my view. It fits well with my view. I hold that the duties that underpin blameworthiness and praiseworthiness are duties of respect. I hold that a more general duty of respect for objective reasons underpins blameworthiness/praiseworthiness in the court of overall reason, which is the same thing as irrationality/rationality. If so, my view yields stringency.

\footnotetext{
32 Cf. Lord and Maguire (2016). Shpall (2014: 158-161) gives great examples I'll mention, though I don't accept his diagnosis of them.
} 
Duties of respect afford illustrations of the stringent but outweighable of a piece with the duty to keep one's promises. They ought to be canonical illustrations, since they are the fundamental grounds of fault. Since I've already argued that we need a duty of respect for objective reasons to back assessments of blameworthiness in the court of overall reason, we can extend the conclusion, and claim that the rational norms grounded by this duty of respect have the same kind of stringency. This is the best we can do to vindicate the objective stringency of rationality, given that one can be required by rationality to do something that there isn't conclusive objective reason to do.

\subsection{What about bootstrapping?}

Another important objection is simple. Bootstrapping seems bad. My account, however, seems to permit bootstrapping. How is this not a reductio of it?

Reply. My strategy here will resemble my strategy for replying to the last objection. I agree that bootstrapping is bad. I disagree, however, that my account permits bootstrapping when we properly understand what bootstrapping is and why it is objectionable.

Sometimes it is claimed a view licenses bootstrapping if it predicts that the belief or appearance that one has a strong reason to $\phi$ gives one a strong reason. But it is implausible that this is all that bootstrapping involves. Many epistemologists think apparent evidence about the quality of one's evidence can affect what it is rational to believe at the first order. It is hard to see how that thought alone legitimates bootstrapping. What seems bad is rather the idea that you can generate a sufficient reason to $\phi$ just by making it seem to yourself that you have sufficient to $\phi$. But my account doesn't tolerate that kind of bootstrapping. It doesn't imply that you can use the sheer fact that it seems to you that you have an undefeated reason to $\phi$ as a basis for justifiably $\phi$-ing.

Respect places constraints not only on what combinations of mental states are permitted, but also on how you reason to new mental states. You cannot manifest respect for reasons by intending to $\phi$ on the basis of the sheer fact that it seems to you that you have sufficient reason to $\phi$. It is also implausible to think that if you delude yourself so that it seems to you that you have an undefeated reason to $\phi$, you are manifesting respect or commitment.

Note also that my account doesn't entail that undefeatedness is transparent: you can believe that you have an undefeated serious reason to $\phi$ without getting an undefeated serious reason to $\phi$. If your belief isn't rational, the duty of respect will require you to drop that belief or ignore it in deliberation. That you would manifest commitment to reasons-responsiveness by heeding your belief does, I think, give you a serious reason to heed that belief. But I don't think this implication by itself is objectionable. This reason is not a sufficient reason. It is equally good by the lights of the commitment norm to abandon an irrational belief if you can do so rationally or to ignore the belief in deliberation if you cannot abandon it rationally (and similarly for non-doxastic seemings). 


\subsection{How are norms of respect objective?}

One might agree that there are norms of respect that underpin local and overall blameworthiness while wondering why we should call these norms 'objective'. Why do that? How can we square this way of talking with the common view that our conclusions about whether someone is blameworthy turn on how this person is heeding her subjective obligations?

Reply. I'll take these questions in reverse. The last question has a simple answer. There is an objective norm we violate by doing something subjectively wrong: the norm of respect. This norm is what makes the subjective 'ought' matter. So, although we can draw conclusions about blameworthiness just on the basis of whether someone has violated their subjective obligations, these conclusions only have normative significance thanks to a more fundamental objective norm.

Of course, this answer assumes that the norm that gives force to the subjective 'ought' is objective. One might still wonder why that is so. To bring out one answer, consider norms of respect in particular domains. Recall the first example I gave in $\S 2$. The actual value of your relationship with Kris called for you to manifest respect for that relationship. You fail to manifest respect for that relationship if you fail to respond to the relevant apparent reasons even if the appearances are factually misleading. A similar point holds for all domain-relative norms of respect. There will be corresponding values-real, not merely apparent-that demand respect. At any rate, this will be plausible if we accept a conception of value that is not essentially teleological—e.g., one like Anderson (1993)'s or Scanlon (1998)'s, on which values are fitting objects of pro-attitudes (which include respect and commitment). But a norm that calls for the fitting response to a value is an objective norm, not a subjective norm.

Does this point still hold if we grant that (dis)respecting Fs doesn't require the existence of any particular Fs that one (dis)respects? It does if we abandon a teleological conception of value and realize that values do not merely include states of affairs. Like Anderson and Scanlon, I view the fitting object of any pro-attitude as a value. It is not just states of affairs and existing objects that can have value in this sense, but also the properties that make particulars valuable or confer normative status. When one manifests respect for other people in a world where the 'other people' are holograms, what makes it true that one is manifesting respect for other people is that one is manifesting respect for the status that attaches to personhood. That status isn't a concretum. But it can be legitimately regarded as a real value if we aren't working with a purely teleological conception of value. Friendship is another example: one can manifest insufficient respect for friendship in a hologram world even if one has no actual friends. As I argued in §2, there is nothing fetishistic about these claims. These claims don't commit us to thinking that respect for particulars is instrumental or secondary. These claims don't entail that caring about properties interferes with non-instrumental caring about particulars.

So, I think we have sufficient reason to regard the norms of respect within particular domains as objective. The norm of respect for overall reason can then be seen as reflecting all values at stake. Given a non-teleological conception of value, 
we can regard norms of respect as value-based. They articulate a fitting way of caring about the important if the important is understood widely (as it should).

\subsection{Don't cases like three envelopes show that rationality isn't about manifesting respect for objective reasons?}

Consider:

Three Envelopes. Chester can choose one of three envelopes. He is correctly told by a reliable informant that there is $\$ 800$ in Envelope 1 . He is also correctly told there is $\$ 1000$ in either Envelope 2 or 3, and that the envelope that lacks it is empty. But he cannot learn anything else about which might contain the $\$ 1000 .^{33}$

Chester ought rationally to pick Envelope 1. But Chester can know that there is more objective reason to do otherwise. For he can know that either (i) there is more objective reason to choose Envelope 2 or (ii) that there is more objective reason to choose Envelope 3. After all, there is $\$ 200$ more in one of them. If this is right, how can rationality require us to manifest respect for objective reasons?

Reply. Randomly picking one of the two envelopes carries a serious risk of getting an envelope there is no objective reason to take. Doing that would manifest disrespect for objective reasons. Since $\$ 800$ provides a good enough objective reason such that heeding it manifests some respect for reasons, and there no other apparent reason such that heeding it would manifest greater respect, the norm of respect recommends Envelope 1. In other words: minimizing expected nonconformity with objective reasons is constitutive of avoiding disrespect and maximizing expected conformity with objective reasons is constitutive of manifesting respect. If we regard maximizing expected conformity with objective reasons to be constitutive of respect for reasons, does that mean that our position simply collapses into a familiar approach? No. Until we realize that maximizing expected conformity with reasons constitutes something further-namely, respect for objective reasons - we are left with no explanation of why failing to minimize expected non-conformity with objective reasons is a mistake. We can only see that it is a mistake by seeing that it would constitute something further: a failure of respect.

\section{Concluding remarks}

Let's take stock. I began with a puzzle. On the one hand, it is hard to see why apparent reasons should be an exception to the truism that apparent Fs needn't be real Fs. On the other hand, it looks like a genuine mistake to ignore the apparent reasons, not merely an apparent mistake. Yet it is hard to see how it could be a genuine mistake unless apparent reasons are an exception to the thought that

\footnotetext{
33 This formulation is from Ross (2012).
} 
apparent Fs need not be real Fs. I observed that this puzzle is more general than the literature assumes and isn't limited to cases in which the appearances are doxastic.

I then proceeded to develop a new solution, which I dubbed the Respect-Based Account. I began by defending the modest claim that for any $\mathrm{X}$ that calls for respect, if we do what appears to violate one of our duties towards $X$, we thereby violate the further duty of respect for X. I marked a number of examples that lent support to this thought, and explained why we cannot accommodate the intuitions about them merely by saying that someone has violated subjective obligations. We need an explanation of why violating one's subjective obligations is a genuine mistake, not merely an apparent mistake. Norms of respect provided a natural explanation.

This argument provided a local vindication of the idea that apparent reasons are exceptions to the independence of appearance and reality. I then generalized these arguments beyond the moral case. Just as norms of respect for moral reasons and commitment to moral reasons-responsiveness underpin charges of moral blameworthiness, so norms of respect for reasons (period) and commitment to reasons-responsiveness (period) underpin charges of blameworthiness in the court of overall reason. But charges of blameworthiness in the court of overall reason just are charges of irrationality.

So the account shows that there are genuine norms that one is violating when one is irrational. The existence of these norms entails that apparent reasons across the board are exceptions to the independence of appearance and reality. Or near enough: The appearances can mislead us about the presence of specific reasons. But if we have an undefeated serious apparent reason, we thereby have a serious real reason. Together with norms of respect, then, appearances generate real reasons.

Acknowledgements This paper was intended to be the final chapter of my dissertation but was composed under its present title in summer 2014; before then, its key example and other ideas had been circulated under the title 'Perspective and the Objectively Normative', a paper written in late 2010 and early 2011, and which was also briefly given the title 'The Objective Significance of the Subjective'. For important feedback on one or more of these papers, thanks are especially owed to Ruth Chang, Alex Gregory, Conor McHugh, Errol Lord, Daniel Singer, Holly Smith, Ernest Sosa, Jonathan Way, Daniel Whiting, two anonymous referees for another journal, one anonymous referee for this journal, members of Daniel J. Singer's 2014 seminar on epistemic normativity, and audiences at Cardiff University and the University of North Carolina at Chapel Hill.

Open Access This article is licensed under a Creative Commons Attribution 4.0 International License, which permits use, sharing, adaptation, distribution and reproduction in any medium or format, as long as you give appropriate credit to the original author(s) and the source, provide a link to the Creative Commons licence, and indicate if changes were made. The images or other third party material in this article are included in the article's Creative Commons licence, unless indicated otherwise in a credit line to the material. If material is not included in the article's Creative Commons licence and your intended use is not permitted by statutory regulation or exceeds the permitted use, you will need to obtain permission directly from the copyright holder. To view a copy of this licence, visit http:// creativecommons.org/licenses/by/4.0/.

\section{References}

Anderson, E. (1993). Value in ethics and economics. Cambridge: Harvard University Press. Arpaly, N. (2003). Unprincipled virtue. OUP. 
Bengson, J. (2015). The intellectual given. Mind, 124, 707-760.

Bratman, M. (2009). Intention, practical rationality, and self--governance. Ethics, 119, 411-443.

Brink, D. O. (1997). Moral motivation. Ethics, 108, 4-32.

Broome, J. (1999). Normative requirements. Ratio, 12, 398-419.

Broome, J. (2005). Does Rationality Give Us Reasons? Philosophical Issues, 15, 321-337.

Broome, J. (2008). Is rationality normative? Disputatio, 11, 153-171.

Broome, J. (2013). Rationality through reasoning. Oxford: Blackwell.

Dancy, J. (2000). Practical reality. OUP.

Dancy, J. (2004). 'Enticing Reasons'. In Wallace, R. J., Pettit, P., Scheffler, S. and Smith, M. (eds.) Reason and Value: Themes from the Moral Philosophy of Joseph Raz. OUP.

Darwall, S. (1977). Two kinds of respect. Ethics, 88, 36-49.

Darwall, S. 2006. The Second-Person Standpoint. Harvard UP.

Dreier, J. (2000). Dispositions and Fetishes: Externalist Models of Moral Motivation. PPR, 61, 619-638.

Fogal, D. (2019) Forthcoming. 'Rational Requirements and the Primacy of Pressure.' Mind.

Graham, P. (2014). A sketch of a theory of moral blameworthiness. Philosophy and Phenomenological Research, 88(2), 388-409.

Holton, R. (2009) Unpublished. 'Inverse Akrasia and Weakness of Will.'

Huemer, M. (2007). Compassionate phenomenal conservatism. PPR, 74, 30-55.

Hussain, N. (2007) MS. 'The Requirements of Rationality.'

Johnson King, Z. (2020a). Accidentally doing the right thing. PPR, 100, 186-206.

Johnson King, Z. (2020b). Praiseworthy motivations. Nous, 54, 408-430.

Kiesewetter, B. 2017. The Normativity of Rationality. OUP.

Kolodny, N. (2005). Why be rational? Mind, 114, 509-560.

Kolodny, N. (2007a). How does coherence matter? Proceedings of the Aristotelian Society, 107, $229-263$.

Kolodny, N. (2007b). State or process requirements? Mind, 116, 371-385.

Kolodny, N. (2008a). The Myth of Practical Consistency. European Journal of Philosophy, 16, 366-402.

Kolodny, N. (2008b). Why Be Disposed to Be Coherent? Ethics, 118, 437-463.

Kriegel, U. (2012). Moral motivation, moral phenomenology, and the alief/belief distinction. Australasian Journal of Philosophy, 90, 469-486.

Lord, E. 2018. The importance of being rational. OUP.

Lord, E. \& Maguire, B. 2016. 'An Opinionated Guide to the Weight of Reasons'. In Lord, E. \& Maguire, B. (eds.) Weighing Reasons. OUP.

Parfit, D. (2001). 'Rationality and reasons' in Exploring practical philosophy. Aldershot: Ashgate.

Parfit, D. (2011). On what matters. OUP.

Raz, J. (2005). The Myth of Instrumental Rationality. JESP, 1, 1.

Raz, J. (2011). From normativity to responsibility. OUP.

Reisner, A. (2011). 'Is there Reason to Be Theoretically Rational?'. In Reisner, A. \& Steglich-Petersen, A. (eds.) Reasons for Belief. Cambridge UP.

Rippon, S. (2011). In defense of the wide-scope instrumental principle. Journal of Ethics and Social Philosophy, 5, 2.

Ross, J. (2012). 'Rationality, Normativity, and Commitment.' Oxford Studies in Metaethics 7. Oxford: Oxford University Press.

Scanlon, T. M. (1998). What we owe to each other. Cambridge: Harvard University Press.

Schroeder, M. (2005). Instrumental mythology. JESP, 1, 1.

Schroeder, M. (2009). Means-end coherence, stringency, and subjective reasons. Philosophy Studies, 143, $223-248$.

Setiya, K. (2007). Cognitivism about Instrumental Reason. Ethics, 117(4), 649-673.

Shpall, S. (2014). Moral and rational commitment. PPR, 88(1), 146-172.

Smith, M. (1994). The moral problem. Oxford: Blackwell.

Smith, M. (2004). The structure of orthonomy. Royal Institute of Philosophy Supplement, 55, 165-193.

Southwood, N. (2008). Vindicating the Normativity of Rationality. Ethics, 119, 9-30.

Sylvan, K. (2012). Truth monism without teleology. Thought, 1(3), 161-169.

Sylvan, K. (2014). On the Normativity of Epistemic Rationality. Ph.D. Thesis, Rutgers University.

Sylvan, K. (2015). What apparent reasons appear to be. Philosophical Studies, 172, 587-606.

Sylvan, K. (2018). Veritism unswamped. Mind, 127, 381-435.

Sylvan, K. (2020). An epistemic non-consequentialism. Philosophical Review, 129, 1-51.

Sylvan, K. and Sosa, E. 2018. 'The Place of Reasons in Epistemology.' In Star, D. (ed.) The Oxford Handbook of Reasons and Normativity. OUP. 
Vogelstein, E. (2012). Subjective reasons. Ethical Theory and Moral Practice, 15, 239-257.

Way, J. (2009). Two accounts of the normativity of rationality. JESP, 4, 2.

Way, J. (2010). Defending the wide -scope approach to instrumental reason. Philosophical Studies, 147, 213-233.

Whiting, D. (2013). Keeping things in perspective: reasons, rationality, and the a priori. JESP, $8,1$.

Wodak, D. (2019). An objectivist's guide to subjective reasons. Res Philosophica, 96, 229-244.

Zimmerman, M. (1997). A plea for accuses. American Philosophical Quarterly, 34, 229-243.

Publisher's Note Springer Nature remains neutral with regard to jurisdictional claims in published maps and institutional affiliations. 